\title{
An innovative correction method of wind speed for efficiency evaluation of wind turbines
}

\author{
Alessio Carullo ${ }^{1}$, Alessandro Ciocia ${ }^{2}$, Gabriele Malgaroli², Filippo Spertino² \\ ${ }^{1}$ Dipartimento di Elettronica e Telecomunicazioni, Politecnico di Torino, corso Duca degli Abruzzi 24, 10129 Turin, Italy \\ 2 Dipartimento Energia, Politecnico di Torino, corso Duca degli Abruzzi 24, 10129 Turin, Italy
}

\begin{abstract}
The performance of horizontal axis Wind Turbines (WTs) is strongly affected by the wind speed entering in their rotor. Generally, this quantity is not available, because the wind speed is measured on the nacelle behind the turbine rotor, providing a lower value. Therefore, two correction methods are usually employed, requiring two input quantities: the wind speed on the back of the turbine nacelle and the wind speed measured by a meteorological mast close to the turbines under analysis. However, the presence of this station in wind farms is rare and the number of WTs in the wind farm is high. This paper proposes an innovative correction, named "Statistical Method" (SM), that evaluates the efficiency of WTs by estimating the wind speed entering in the WTs rotor. This method relies on the manufacturer power curve and the data measured by the WT anemometer only, thus having the possibility to be employed also in wind farms without a meteorological station. The effectiveness of such a method is discussed by comparing the results obtained through the standard methods implemented on two turbines (rated power = 1.5 MW and 2.5 MW) of a wind power plant (nominal power = $80 \mathrm{MW}$ ) in Southern Italy.
\end{abstract}

\section{Section: RESEARCH PAPER}

Keywords: Renewable energy sources; wind energy systems; wind speed; power measurement; uncertainty

Citation: Alessio Carullo, Alessandro Ciocia, Gabriele Malgaroli, Filippo Spertino, An innovative correction method of wind speed for efficiency evaluation of wind turbines, Acta IMEKO, vol. 10, no. 2, article 8, June 2021, identifier: IMEKO-ACTA-10 (2021)-02-08

Section Editor: Ciro Spataro, University of Palermo, Italy

Received January 15, 2021; In final form April 28, 2021; Published June 2021

Copyright: This is an open-access article distributed under the terms of the Creative Commons Attribution 3.0 License, which permits unrestricted use, distribution, and reproduction in any medium, provided the original author and source are credited.

Corresponding author: Alessio Carullo, e-mail: alessio.carullo@polito.it

\section{INTRODUCTION}

The increasing energy demand and the requirements of minimal environmental impact have pushed towards to a huge increase of Renewable Energy Sources (RES). A drawback of these sources is their intermittency, which can be mitigated by means of the integration of storage units, e.g. electrochemical batteries [1]-[3]. Among the RES, Wind Turbines (WTs) represent a reliable and clean source of electricity with low marginal costs [3]. New wind power plants have been installed in Europe in 2020 , with a cumulative rated power of about $7 \mathrm{GW}$, and an increase of about $10 \mathrm{GW}$ is expected in 2021, thus reaching a cumulative capacity of about $250 \mathrm{GW}$ [4]. In this framework, offshore applications will represent about $20 \%$ of new installations in the period 2020-2023, especially in the Netherlands, Ireland, Norway and France.

WTs can work at fixed speed or variable speed, and the latter are able to adjust the rotor speed, thus following the maximum aerodynamic power of the wind [5]. On the other hand, their control requires the wind speed to be measured through an anemometer, thus increasing the overall cost and the size of the system. The anemometer is usually located on the back of the turbine, where a wind speed that is lower than the wind speed entering in the rotor is measured. For this reason, the use of the measurement of this anemometer leads WTs to exhibit experimental performance that seems better than their nameplate specification, since the manufacturer states the power curve with reference to the wind speed at the entrance of the rotor. In addition, manufacturer-stated performance refers to ideal conditions of minimum turbulence, flat terrain and absence of wakes due to obstacles [6]. A reliable estimation of WT performance then requires the measured wind speed to be corrected and, for this reason, two different correction methods have been defined in technical specifications and International Standards. The first method does not take into account the effects of the wakes of other turbines and obstacles, while the second method filters the considered direction of the wind in order to remove these wake effects. Wake is a sort of loading effect, as occurs in electric circuits. Wakes are long trails of wind 
in turbulent regime and with lower speed with respect to the entrance of turbines rotor. This effect needs to be minimized because if the wind flow entering in the WT rotor is affected by the wake of another turbine, its speed is lower than in the wakefree conditions, i.e. energy production is reduced. A common requirement of these methods is the availability of two quantities: the wind speed $\nu_{\mathrm{WT}}$ measured by the anemometer and the wind speed $v_{\text {stat }}$ detected by a meteorological mast, which has to be close to the turbine under investigation. Unfortunately, a meteorological mast is not always present in wind power plants, thus preventing the implementation of these correction methods.

To overcome this limitation, the present work proposes an alternative method that relies on the manufacturer power curve and the wind speed detected by the turbine anemometer, thus not requiring the measurements provided by a meteorological mast.

In Section 2, a review of the two standard methods is presented and the new correction method is described. Section 3 defines the concept of yearly average efficiency (which takes into account the energy generated by a WT), and describes the parameters availability and capacity factor. In Section 4, a case study is presented related to a wind power plant in Southern Italy. Section 5 reports the obtained results for two different WTs that are located in two different areas of the considered power plant. Finally, Section 6 summarizes the main outcomes of this work.

\section{CORRECTION METHODS}

An expansion of the stream tube occurs before and after the passage in the three-blade rotor. Therefore, the cross section of the wind flow increases, while its kinetic energy (thus, its speed) decreases. The presented methods aim to correct the wind speed detected by the anemometer behind the turbine rotor, calculating the corresponding speed at its entrance.

Before the application of one of the proposed correction methods, a preliminary normalization to the reference air density $\varrho_{\text {ref }}=1.225 \mathrm{~kg} / \mathrm{m}^{3}$ is performed, since manufacturer specifications refer to this condition. In particular, for WTs with active power control, experimental results are corrected according to the following expression [6]:

$$
v_{\text {cor }}=v_{\text {exp }} \cdot\left(\frac{\rho_{\text {air }}}{\rho_{\text {ref }}}\right)^{1 / 3} \text {, }
$$

where $v_{\text {cor }}$ is the corrected wind speed, $v_{\text {exp }}$ is the measured wind speed and $\varrho_{\text {air }}$ is the air density during the measurement.

\subsection{Method \#1 - Straight Line Method (SLM)}

The first method requires $v_{\mathrm{WT}}$ and $v_{\text {stat }}$ as input quantities, and consists of the following steps:

1) Step A - Selection of the wind-speed direction.

The wind direction $\beta$ is properly selected in order to consider valid the assumption $v_{\text {stat }} \approx v_{\text {entr }}$, where $v_{\text {entr }}$ is the wind speed that enters in the turbine rotor. In particular, experimental results are filtered in order to analyse the wind contributions flowing from the station to the WT. Assuming to simplify the problem as a $2 \mathrm{D}$ system without the vertical coordinate, a straight line is traced between the anemometric station and the WT under test and its orientation $\beta_{\mathrm{WT}}$ with respect to the North direction is calculated. However, if the set of experimental data is limited, a low number of experimental points is available. In this case, it is generally convenient to extend the analysis to wind speeds with orientations $\beta=\beta_{\mathrm{WT}} \pm \Delta \beta$, where $2 \Delta \beta$ is the top angle of a triangle whose base is the rotor diameter $D$ of the $\mathrm{WT}\left(D=2 \cdot r_{\mathrm{d}}\right.$, by assumption, where $r_{\mathrm{d}}$ is the length of a blade, neglecting the hub radius) and the third vertex of the triangle is the meteorological mast.

2) Step B - Selection of data with $v_{\text {entr }}>\iota_{\text {vт }}$. As described in the step A, the wind speeds of interest flow from the anemometric station to the WT. Therefore, $v_{\text {entr }}$ has to be larger than $\nu_{\mathrm{VT}}$ because the kinetic energy of the wind decreases when it flows through the meteorological mast.

3) Step C - Removal of experimental data with turbulence larger than $10 \%$.

In each time interval, the turbulence is the ratio between the standard deviation of the wind speed and its average value in the interval. The power curve provided by the manufacturer is measured in conditions of minimum turbulence, which is generally lower than $10 \%$ [7].

4) Step D - Linear regression of experimental data.

In this step, a linear equation that describes $v_{\text {stat }}$ as a function of $\nu_{\mathrm{wT}}$ is identified in order to estimate $v_{\text {entr }}$ by the line of regression of $v_{\text {stat }}$ on $\nu_{\mathrm{TT}}$, where the measurement of $\iota_{\mathrm{VT}}$ is corrected thanks to the measurement of $v_{\text {stat. }}$. The goodness-of-fit of the linear regression to the experimental data is measured through the parameter $R^{2}$, which ranges from 0 (no suitable model) to 1 (best model).

During the design of a wind power plant, the position of the turbines has to be optimized in order to minimize their mutual wakes and maximize their energy production. However, due to different constraints, such as terrains and land morphology, these effects cannot be always minimized. Therefore, the first method needs to be modified in order to remove possible errors due to mutual wakes effect.

\subsection{Method \#2 - No Wakes Method (NWM)}

This method is similar to and consists of the same steps as the SLM. However, since NWM aims to avoid the mutual wakes that affect the measurements, step A is modified. Indeed, NWM does not focus the correction on the direction joining the meteorological mast and the WT; on the contrary, it investigates all the directions in which the anemometric station and the WT are not affected by the wakes of other turbines. The procedure used to determine the wind directions disengaged from any obstacles is based on the document [6]. In particular, for each obstacle in the neighbourhood of the WT, such as other operating WTs or a meteorological station, the wind direction angles $\alpha$ that must be excluded from the analysis are calculated according to this expression:

$$
\alpha=1.3 \cdot \arctan \left(\frac{2.5 \cdot D}{L}+0.15\right)+10,
$$

where $D$ is the rotor diameter and $L$ is the mutual distance between the obstacle and the WT under test.

After the selection of the proper wind direction, it is possible to verify the validity of the results thanks to a more sophisticated analytical model, which is named the "Jensen Model" or "Park Model" [8]. It permits to estimate the wind speed $v^{*}$ perturbed by the wake of a turbine using the following expression: 


$$
v^{*}=v_{0} \cdot\left[1-\frac{1-\sqrt{1-C_{T}}}{\left(1+\frac{k \cdot x}{r_{d}}\right)^{2}}\right],
$$

where $v_{0}$ is the wind speed not affected by wakes, $C_{\mathrm{T}}$ is the thrust coefficient of a WT and depends on the wind intensity, $r_{\mathrm{d}}$ is the radius of the turbine rotor, and $x$ is the downwind distance. The parameter $k$ is the decay constant of the wake that is estimated according to the following equation:

$$
k=\frac{0.5}{\ln \left(\frac{h}{z_{0}}\right)},
$$

where $b$ is the hub height of the WT and $z_{0}$ is the roughness of the ground. According to Jensen model, the wake increases linearly with $x$ and its diffusion radius $r_{\mathrm{x}}$ can be estimated as:

$$
r_{x}=r_{d}+k \cdot x \text {. }
$$

It should be noted that the model considers the perturbation of the flow profile along the direction of the wind, while its perpendicular component is assumed constant (1-D model). Finally, this model assumes that $k$ is a constant parameter that depends only on $b$ and $z 0$.

\subsection{Method \#3 - Statistical Method (SM)}

The alternative method does not require experimental data provided by a meteorological station [9]: the input quantities are the wind speed measured by the WT anemometer and the power curve provided by the manufacturer. The assumption behind this methodology is that the power curve of the WT manufacturer is the locus of the points where the generator operates with the best performance. Therefore, the analytic relation between $\imath_{\mathrm{WT}}$ and the wind speed provided by the WT manufacturer (for the same output electric power $P_{\mathrm{k}}$ ) is derived. Figure 1 reports the scheme

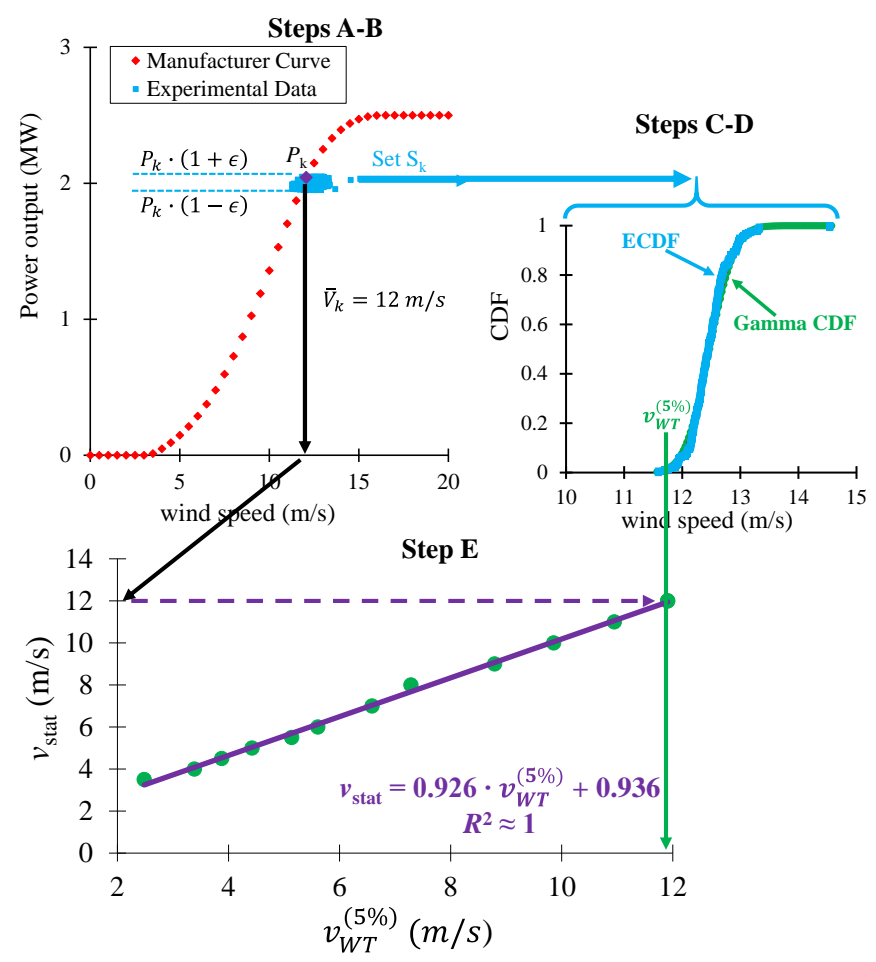

Figure 1. Scheme of the methodology for the SM. of the aforementioned methodology. More in detail, the methodology consists of the following steps:

1) Step A - Removal of experimental data with turbulence larger than $10 \%$ [7];

2) Step B - Selection of the experimental set $S_{\mathrm{k}}$. One of the available working point $P_{\mathrm{k}}=\mathrm{P}\left(\nu_{\mathrm{k}}\right)$ is selected on the power curve provided by the WT manufacturer. Then, a set $S_{\mathrm{k}}$ of experimental data is identified such that the electric output power lies in the neighbourhood of $P_{\mathrm{k}}$, i.e. in the interval between $P_{\mathrm{k}} \cdot(1-\varepsilon)$ and $P_{\mathrm{k}} \cdot(1+\varepsilon)$. In this work, the value of $\varepsilon$ was set to 0.01 , based on the consideration that output powers within a $\pm 1 \%$ interval are not distinguishable due to the typical uncertainty of the equipment that is used to measure this quantity. The set $S_{\mathrm{k}}$ is described as:

$$
\begin{gathered}
S_{k}=\left\{\left[v_{\mathrm{WT}, i}, P\left(v_{\mathrm{WT}, i}\right)\right]:\right. \\
\left.P\left(v_{\mathrm{WT}, i}\right) \in\left[P_{k} \cdot(1-\varepsilon) \div P_{k} \cdot(1+\varepsilon)\right]\right\} .
\end{gathered}
$$

3) Step C - Calculation of the Empiric Cumulative Distribution Function (ECDF) of the wind speed.

The ECDF of the wind speed corresponding to the selected value of $\nu_{\mathrm{k}}$ is calculated, as shown in Figure 2 (blue dots), which refers to the value $v_{\mathrm{k}}=12 \mathrm{~m} / \mathrm{s}$. The same figure also highlights how the calculated ECDF is well approximated by the $\mathrm{CDF} F\left(\nu_{\mathrm{WT}}\right)$ (red line) corresponding to the Probability Density Function (PDF) $f\left(\nu_{\mathrm{WT}}\right)$ of the known factorial function $\Gamma[10]$ :

$$
f\left(v_{\mathrm{WT}}\right)=\frac{v_{\mathrm{WT}}^{a-1}}{b^{a} \cdot \Gamma(a)} \cdot e^{-\frac{v_{\mathrm{WT}}}{b}} \quad\left(v_{\mathrm{WT}} \geq 0\right)
$$

where the parameter $a$ is estimated as the square ratio between the mean value and the standard deviation of $S_{\mathrm{k}}$, while the parameter $b$ is derived as the ratio between the mean value of $S_{\mathrm{k}}$ and $a$;

4) Step D - Estimation of the wind-speed fifth percentile. Starting from the PDF $f\left(\nu_{\mathrm{WT}}\right)$, the fifth percentile $v_{\mathrm{WT}}^{5 \%}$ of the wind speed, i.e. the value that has the $5 \%$ of probability to not be exceeded in $S_{\mathrm{k}}$, is selected;

Steps from B to D are repeated for each available working point $P\left(\nu_{\mathrm{k}}\right)$ in the power curve provided by the manufacturer.

5) Step E - Linear regression of experimental data.

This step is similar to step D of the other methods, but in this case a linear equation is obtained between $v_{\mathrm{WT}}^{5 \%}$ and the corresponding $v_{\mathrm{k}}$.

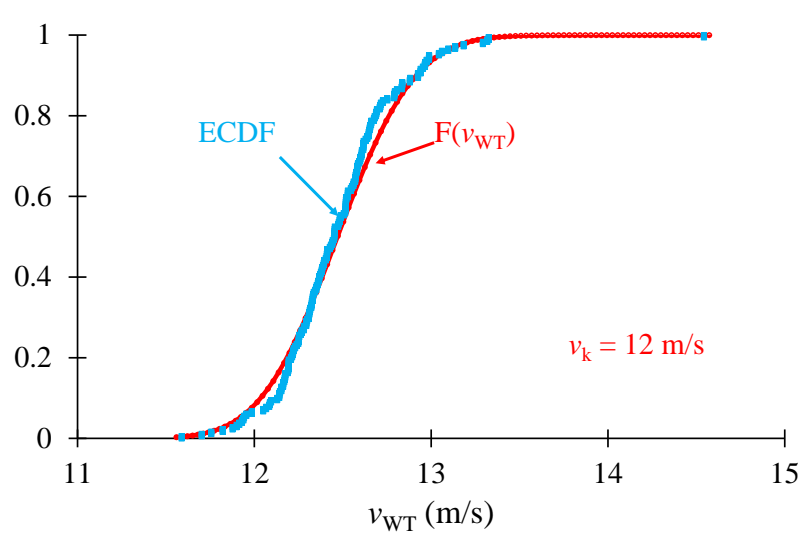

Figure 2. Example of calculated ECDF for $v_{k}=12 \mathrm{~m} / \mathrm{s}$. 
One should note that when the WT reaches its nominal power, the correspondence between the wind speed and the output power is not unique. The output power is indeed limited to the rated value and it can be obtained with several values of the wind speed. This represents a limit of the proposed method, which is not applicable in the range of high wind speeds due to its strong dependence on the power curve of the WT manufacturer.

\section{ESTIMATION OF WT EFFICIENCY}

The efficiency of a WT is the ratio between the electrical power it produces and the aerodynamic power of the wind at the entrance of the rotor. The aerodynamic power $P_{\text {aer }}$ of the wind can be calculated as [11]:

$$
P_{\text {aer }}=\frac{1}{2} \cdot \rho_{\text {air }} \cdot \frac{\pi}{4} \cdot D^{2} \cdot v_{\text {entr }}^{3} .
$$

The efficiency can be also estimated as the ratio between electrical and wind energies in a certain time interval $\Delta t$. Indicating the measured WT output power as $P_{\text {out }}$, the efficiency can be obtained as [12]-[13]:

$$
\eta=\frac{P_{\text {out }}}{P_{\text {aer }}}=\frac{P_{\text {out }} \cdot \Delta t}{P_{\text {aer }} \cdot \Delta t}=\frac{E_{\mathrm{el}}}{E_{\text {aer }}},
$$

where $E_{\mathrm{el}}$ and $E_{\mathrm{aer}}$ are electrical and aerodynamic energies, respectively.

With the aim of comparing the three proposed correction methods, the results will be expressed in terms of weighted yearly efficiency $\eta^{*}$ :

$$
\eta^{*}=\frac{\sum_{\text {year }}\left(\eta_{k} \cdot E_{k}\right)}{\sum_{\text {year }}\left(E_{k}\right)}=\frac{\sum_{\text {year }}\left(\eta_{k} \cdot E_{k}\right)}{E_{\mathrm{y}, \exp }}
$$

where $\eta_{\mathrm{k}}$ is the W'T efficiency, $E_{\mathrm{k}}$ is the output energy in the $k$ th time interval ( $\Delta t=10 \mathrm{~min})$, and $E_{\mathrm{y}, \exp }$ is the experimental yearly energy generated by the WT.

Thanks to the availability of an anemometric station and to the accurate selection of the wind direction, the NWM is considered as the reference method. The other two methods will be then compared to the NWM by means of the efficiency deviation $\Delta \eta^{*}$, which is defined as:

$$
\Delta \eta^{*}=100 \% \cdot \frac{\eta^{*}-\eta_{\mathrm{NWM}}^{*}}{\eta_{\mathrm{NWM}}^{*}}
$$

where $\eta_{\mathrm{NWM}}^{*}$ is the average efficiency estimated with the NWM.

Moreover, the availability factor and the capacity factor are calculated for the turbines under analysis. The first quantity provides information regarding the probability that a system is operational at a specific time: in particular, it is the ratio between the uptime of WTs and their total operation time, which includes non-operation periods due to failures or maintenance actions [14]-[15]. On the other hand, the capacity factor is, for a given time interval, the ratio between the real energy produced and injected into the grid, and the ideal energy that could be generated by the turbine working continuously at its rated power. An example of centralized power station with very high capacity factor (about $90 \%$ of one year) are units for base load operation.

\section{CASE STUDY}

The three methods previously described were applied to two WTs of a wind farm in Southern Italy (with 43 W'Ts, global nominal power of $80 \mathrm{MW}$ and altitude between $1100 \mathrm{~m}$ and
$1200 \mathrm{~m}$ ) using data collected during a measurement campaign in 2017. The turbines of the wind farm have hub height of $80 \mathrm{~m}$ and a three-bladed rotor. Their wind speed range is the following: cut-in speed $v_{\text {c-in }}=3.5 \mathrm{~m} / \mathrm{s}$, cut-out speed $v_{\text {c-out }}=25 \mathrm{~m} / \mathrm{s}$. However, the wind farm is divided in two parts, with two different models of turbines. In the first area, WTs have a nominal power of $2.5 \mathrm{MW}$, a rotor diameter of $80 \mathrm{~m}$ and rated wind speed of $15 \mathrm{~m} / \mathrm{s}$. In this part, a meteorological mast (height of about $80 \mathrm{~m}$ ) is present, measuring the quantities of interest. In particular, it is equipped with:

1) a First Class cup anemometer, which acquires the horizontal component of the wind speed according to the requirements provided in [6];

2) First Class sensors that detect the wind direction according to [7];

3) pressure, humidity and temperature sensors, which measure the environmental quantities that are used to estimate the air density at the height of meteorological mast and turbine.

The anemometer provides a resolution of $0.05 \mathrm{~m} / \mathrm{s}$ and its stated uncertainty is $\pm 1 \%$ of the measured value in the range $(0.3 \div 50) \mathrm{m} / \mathrm{s}$ with a minimum uncertainty of $\pm 0.2 \mathrm{~m} / \mathrm{s}$. The environmental quantities are measured with uncertainties of $\pm 2{ }^{\circ} \mathrm{C}$ for the temperature, $\pm 5 \% \mathrm{RH}$ for the relative humidity and $\pm 1 \mathrm{kPa}$ for the pressure.

In the second area of the wind farm, WTs have a rated power of $1.5 \mathrm{MW}$, a rotor diameter of $77 \mathrm{~m}$ and a rated wind speed of $12 \mathrm{~m} / \mathrm{s}$. However, in this area, there is no meteorological station installed; hence, the only data available are provided by the anemometer located on the back of the turbines.

Regarding the WTs of the entire plant, they are equipped with an ultrasonic anemometer that measures the absolute value and the direction of the wind speed, providing a resolution of $0.01 \mathrm{~m} / \mathrm{s}$ and an uncertainty of $\pm 2 \%$ of the measured value in the range $(0 \div 60) \mathrm{m} / \mathrm{s}$ (minimum uncertainty $\pm 0.25 \mathrm{~m} / \mathrm{s}$ ). The electrical output power of the WTs is measured with a relative standard uncertainty of $1 \%$.

\section{RESULTS}

\subsection{Results of one turbine with the meteorological station}

In this subsection, the results for a WT in the first area of the wind farm (which is the one equipped with a meteorological mast) are presented. The electrical power measurements $P_{\text {out }}$ obtained at the output of the WT (average values within 10 min time intervals) are shown in Figure 3 (blue points) with respect to the measured wind speed, which is corrected according to equation (1). In the same figure, which refers to results that are collected during a time interval of approximately one year, the manufacturer power curve (red line) is also reported. One should note that a high number of observations are on the left of the manufacturer power curve, since no correction methods are applied to these experimental results. This behaviour is not realistic, since the experimental performance of the WT cannot be higher than the manufacturer's specifications. Furthermore, the cut-in and cut-out wind speeds are about $3 \mathrm{~m} / \mathrm{s}$ and $24 \mathrm{~m} / \mathrm{s}$, respectively, which are lower than the corresponding nominal values $\left(v_{\text {c-in }}=3.5 \mathrm{~m} / \mathrm{s}, v_{\text {c-out }}=25 \mathrm{~m} / \mathrm{s}\right)$.

According to the correction methods described in Section II, experimental results that show turbulence larger than $10 \%$ are removed. Furthermore, also results showing null output power for wind speed in the range $\left(v_{\mathrm{c}-\text { in }} \div v_{\mathrm{c} \text {-out }}\right)$ are removed, since they refer to failure conditions of the investigated plant. Before 


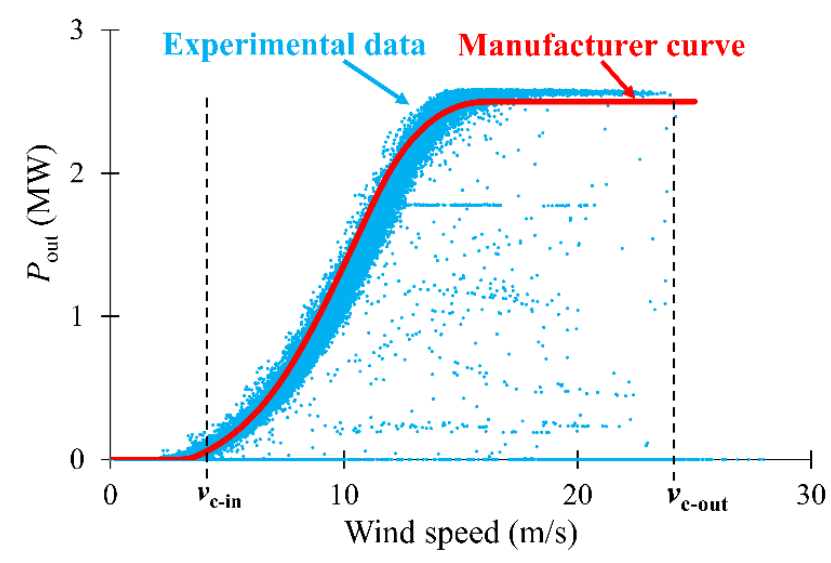

Figure 3. Turbine \#1 - Uncorrected raw experimental data (blue dots) and manufacturer power curve (red line).

applying the described correction methods, a preliminary uncertainty estimation is performed, taking into account the instrumental uncertainty of wattmeter and anemometer of the W'T and the contribution related to the repeatability of the measured output power. As a first step, the method of bins [16] is applied: power measurements are grouped according to the corresponding wind speed measured by the WT anemometer. Since its uncertainty has a maximum value of $0.5 \mathrm{~m} / \mathrm{s}$ for wind speed value of $25 \mathrm{~m} / \mathrm{s}$, experimental results are grouped in uniform wind-speed bins with a width of $\pm 0.5 \mathrm{~m} / \mathrm{s}$.

Then, the mean output power is estimated for each identified group and the standard deviation of the mean is considered as the estimation of the measurement repeatability. This contribution is combined to the instrumental standard uncertainty ( $1 \%$ of the measured value), thus obtaining the combined standard uncertainty $u(P)$. The obtained results are summarized in Figure 4, where the red bars refer to the manufacturer power curve, while the grey bars represent the experimental means of each group centred around integer values of wind speed. The error bars superimposed to each grey bar are the intervals $P_{\text {mean, }} \pm u\left(P_{\mathrm{i}}\right)$. Even though the anomalous data points are removed, the uncorrected experimental results are not fully consistent with the manufacturer specifications yet: for wind-speeds up to $6 \mathrm{~m} / \mathrm{s}$ and at $21 \mathrm{~m} / \mathrm{s}$, the electrical output power is higher than the manufacturer specifications, and cut-in and cut-out wind speeds remain the same previously estimated.

Implementing the SLM, the wind speed direction considered in the correction is $\beta=(231 \pm 13)^{\circ}$ and the linear regression $\left(R^{2}=0.969\right)$ results in the following equation:

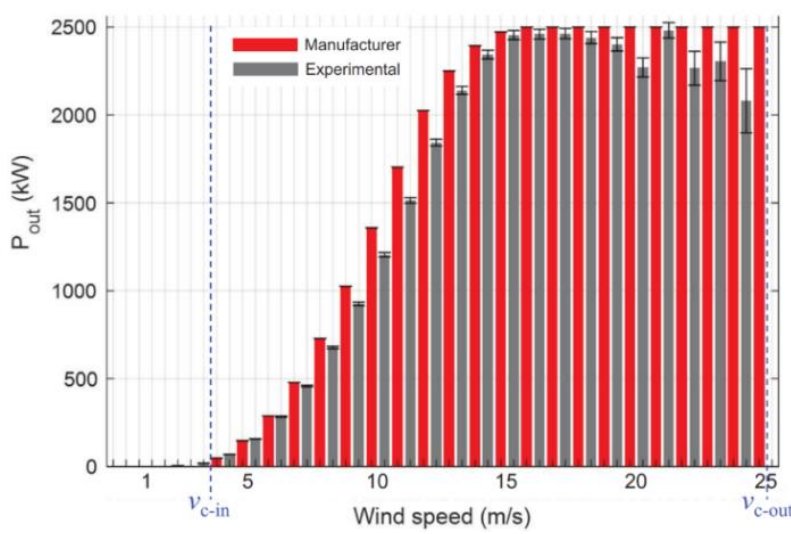

Figure 4. Turbine \#1 - Uncorrected experimental data after the preliminary data processing.

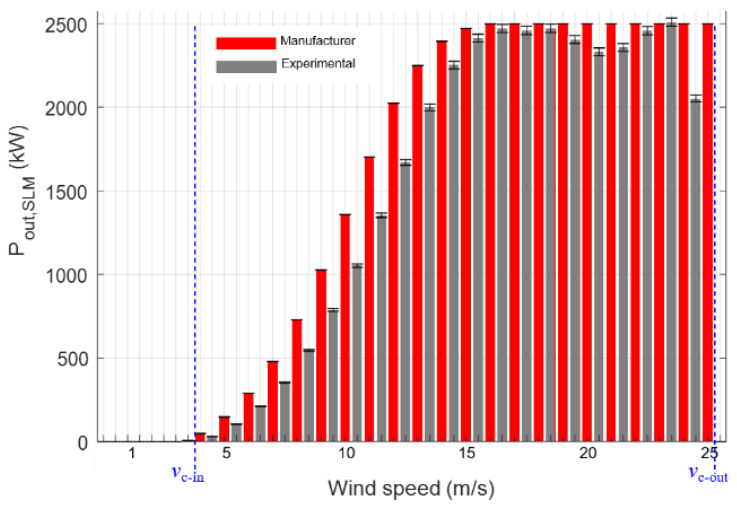

Figure 5. Turbine \#1 - SLM corrected results (grey bars) and manufacturer power curve (red bars).

$$
v_{\text {stat }}=0.971 \cdot v_{W T}+0.758
$$

The results after the correction with equation (12) are reported in Figure 5. For wind speeds lower than $21 \mathrm{~m} / \mathrm{s}$, the corrected output power is lower than the manufacturer curve. Regarding cut-in and cut-out wind speeds, the SLM correction leads to an estimation of $v_{\text {c-in }}$ that is comparable to the rated specification $(\approx 3.5 \mathrm{~m} / \mathrm{s})$, while $v_{\text {c-out }}$ remains lower $(\approx 24 \mathrm{~m} / \mathrm{s})$. Moreover, for wind speeds higher than $13 \mathrm{~m} / \mathrm{s}$, the manufacturer power curve reaches a saturation power of about $2.5 \mathrm{MW}$, while the experimental data reach a higher saturation power. This behaviour is realistic, being due to the pitch regulation of the W'T: in fact, the turbine is allowed to work with a maximum power of about $104 \%$ of rated data. This performance of the WT results in a higher energy production; however, an earlier aging of the turbine due to a higher degradation of the materials may occur as well.

The direction of the wind speeds considered in the SLM may be affected by turbulence, mainly due to the wakes of other turbines or obstacles. The NWM permits to solve this issue by identifying the wind speed directions in which the turbine and the meteorological mast are not affected by wakes. According to Jensen model, the angular section not affected by wakes corresponds to $\beta$ ranging between $-26.8^{\circ}$ and $12.7^{\circ}$ : thus, the North direction $\left(\beta=0^{\circ}\right)$ is selected for the NWM. Figure 6 presents the results of Jensen model for the wind directions considered in the SLM and the NWM using $k=0.075, h=80 \mathrm{~m}$, $r_{\mathrm{d}}=40 \mathrm{~m}$, and $z_{0}=0.1 \mathrm{~m}$. The blue and the red circles represent the WT under analysis and the meteorological mast, respectively; the grey circles indicate the other wind generators, and the cones represent the areas affected by wakes.

With the wind direction assumed for the SLM, the WT and the station are affected by the wake of another turbine; on the other hand, with North direction, they are wake-free. The resulting regression equation $\left(R^{2}=0.979\right)$ for the NWM is the following:

$$
v_{\text {stat }}=0.998 \cdot v_{\mathrm{WT}}+0.550
$$

Figure 7 reports the results after the correction. The NWM correctly estimates the cut-in and cut-out wind speeds as they coincide with the values provided by the manufacturer $(\approx 3.5 \mathrm{~m} / \mathrm{s}$ and $\approx 25 \mathrm{~m} / \mathrm{s}$, respectively).

The SM does not require experimental data from a meteorological mast, thus it can be used also in wind power plants without weather stations close to the WTs. However, as described in Section 2, this correction cannot be applied to the 

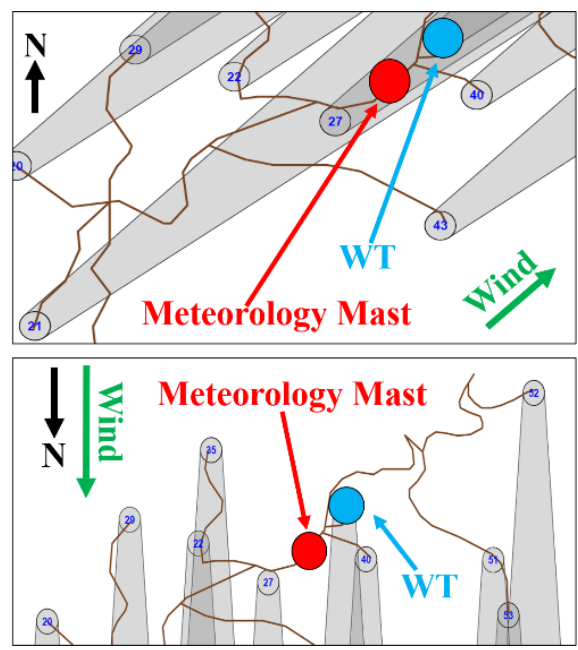

Figure 6. Turbine \#1 - Jensen model with wind directions assumed for SLM (top) and NWM (bottom).

last part of the power curve, where the electrical power reaches a saturation value (the nominal power). Thus, the SM is applied to wind speeds in the range $(4 \div 15) \mathrm{m} / \mathrm{s}$, which is the rated wind speed by the manufacturer. However, the local distribution of experimental wind speeds for the year under study (red bars in Figure 8) shows that this range contains most of experimental data. Actually, for wind speeds of $\approx 15 \mathrm{~m} / \mathrm{s}$, the corresponding cumulative function (blue curve) is higher than 0.93 , i.e. more than $93 \%$ of wind speeds are $\leq 15 \mathrm{~m} / \mathrm{s}$. In order to achieve a better accuracy, regression equations are identified for two wind speed ranges: lower than $6 \mathrm{~m} / \mathrm{s}$, and between $6 \mathrm{~m} / \mathrm{s}$ and $15 \mathrm{~m} / \mathrm{s}$. The resulting equations are the following $\left(R^{2} \approx 1\right)$ :

$$
\begin{aligned}
& v_{\text {stat }}=0.779 \cdot v_{\mathrm{WT}}+1.493 ; v_{\mathrm{WT}}<6 \frac{\mathrm{m}}{\mathrm{s}} \\
& v_{\text {stat }}=0.923 \cdot v_{\mathrm{WT}}+0.961 ; 6 \frac{\mathrm{m}}{\mathrm{s}} \leq v_{\mathrm{WT}}<15 \frac{\mathrm{m}}{\mathrm{s}}
\end{aligned}
$$

The results of the SM, which are reported in Figure 9, highlight that the performance of the WT is now realistic, since it is lower than manufacturer power curve.

The weighted yearly efficiencies are calculated on a yearly basis to evaluate the effectiveness of the corrections (Figure 10). For wind speeds higher than the rated value, the curves converge into the manufacturer data (blue curve), while at lower wind speeds uncorrected data (red curve) have a different shape from the manufacturer curve. Moreover, at low wind speeds, the necessity to correct raw data is evident: in fact, at a wind speed

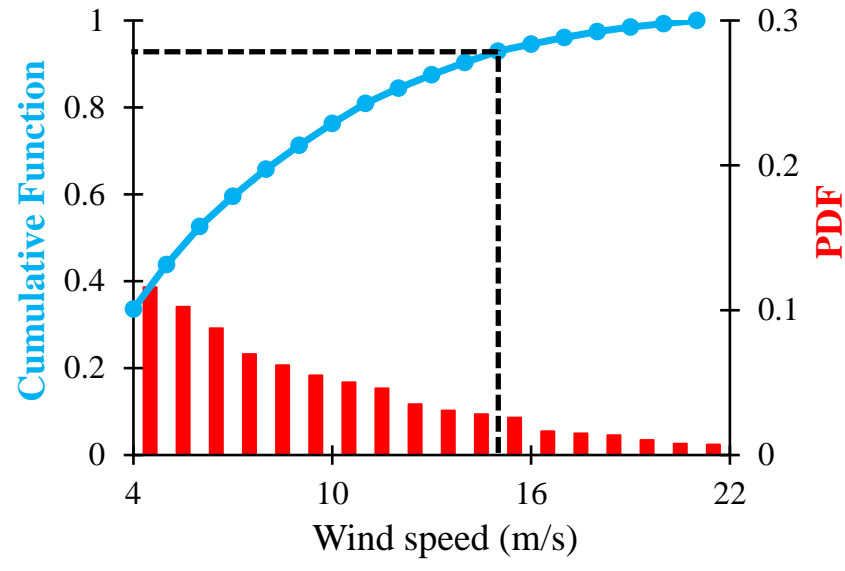

Figure 8. Cumulative function and PDF of wind speed distribution.

of $\approx 5 \mathrm{~m} / \mathrm{s}$, the raw weighted efficiency $\left(\eta^{*} \approx 0.4\right)$ is higher than manufacturer value. Actually, uncorrected data are based on the wind speed detected on the back of the turbine rotor: this value is lower than the wind speed entering the turbine, leading to an overestimation of its efficiency. Regarding the corrections, the SLM (green curve) estimates the lowest efficiencies, but, as previously described, its results are affected by wakes. Indeed, the comparison with the NWM curve shows that the presence of wakes leads to an underestimation of the efficiency. The shape of the efficiency curve of the SM, which is based on the manufacturer data, is the closest to the shape of the manufacturer one.

Table 1 reports the weighted yearly efficiencies and the deviations of the SLM and the SM with respect to the NWM, which is assumed as the reference. For wind speeds $<6 \mathrm{~m} / \mathrm{s}$, the two methods underestimate the efficiency, with similar deviations from the NWM of about $-9.1 \%$ (SLM) and $-7.9 \%$ $(\mathrm{SM})$. In the intermediate wind speeds range $(6 \div 15) \mathrm{m} / \mathrm{s}$, the SLM underestimates the efficiency with a spread of about $-3.5 \%$, while the performance of the WT is overestimated by the SM with a deviation of about $5.2 \%$.

The turbine under analysis has very high energy performance in the area of the farm with the meteorological mast. Its availability and capacity factors are evaluated: the WT under study is in operation for $97.2 \%$ of time, with an average capacity factor of $29.3 \%$. Among the turbines in this part of the wind farm, the performance of this WT is one of the best, being the average availability and capacity factors of the plant equal to $96.5 \%$ and $22.3 \%$, respectively.

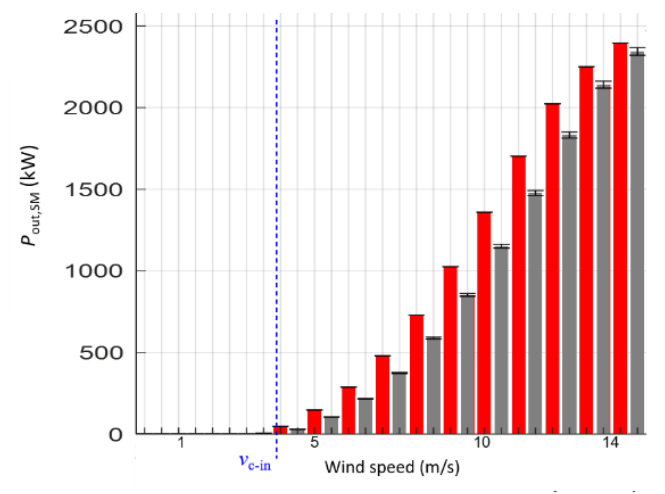

Figure 9. Turbine \#1 - SM corrected results (grey bars) and manufacturer power curve (red bars).
Figure 7. Turbine \#1 - NWM corrected results (grey bars) and manufacturer power curve (red bars).

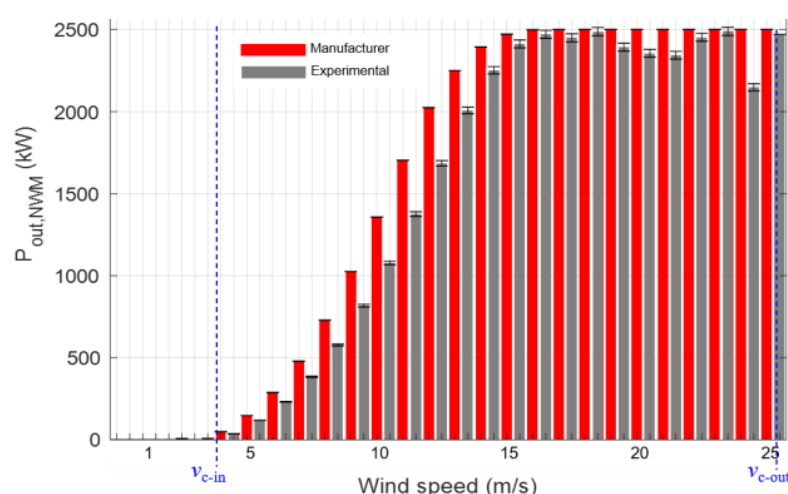

ACTA IMEKO | www.imeko.org 
Table 1. Weighted yearly efficiencies and deviations for the correction methods (turbine with meteorological station).

\begin{tabular}{ccccccc}
\hline $\begin{array}{c}\text { Wind Speed } \\
\text { Range }\end{array}$ & $\boldsymbol{\eta}_{\text {raw }}^{*}$ & $\boldsymbol{\eta}_{\text {SLM }}^{*}$ & $\boldsymbol{\eta}_{\text {NWM }}^{*}$ & $\boldsymbol{\eta}_{\text {SM }}^{*}$ & $\Delta \boldsymbol{\eta}_{\text {SLM }}^{*}$ & $\Delta \boldsymbol{\eta}_{\text {SM }}^{*}$ \\
\hline$<6 \mathrm{~m} / \mathrm{s}$ & 39.7 & $30.0 \%$ & $33.0 \%$ & $30.0 \%$ & $-9.1 \%$ & $-7.9 \%$ \\
$6-15 \mathrm{~m} / \mathrm{s}$ & 39.9 & $33.7 \%$ & $34.8 \%$ & $37.0 \%$ & $-3.5 \%$ & $5.2 \%$ \\
\hline
\end{tabular}

\subsection{Results of one turbine without the meteorological station}

This subsection presents the results for a WT in the second area of the wind farm (i.e., without the meteorological mast). The power curve provided by the manufacturer (red line) and experimental observations (blue points, corresponding to average $P_{\text {out }}$ values within 10 min time intervals) are presented in Figure 11; the wind speeds are corrected according to equation (1). In Figure 11, a high number of data are shifted on the left of the manufacturer power curve. Moreover, the cut-in and the cut-out wind speeds $(\approx 3 \mathrm{~m} / \mathrm{s}$ and $\approx 20 \mathrm{~m} / \mathrm{s}$ ) are lower than the nominal values $\left(v_{\text {c-in }}=3.5 \mathrm{~m} / \mathrm{s}, v_{\text {c-out }}=25 \mathrm{~m} / \mathrm{s}\right)$ : thus, a correction of these data is required. First, failure conditions are excluded from the analysis by removing observations exhibiting turbulence higher than $10 \%$ and null output power. As described in the previous subsection, a preliminary uncertainty estimation is performed starting from the instrumental uncertainty of the WT wattmeter and anemometer, and the repeatability of the measured output power. Figure 12 shows the results of this preliminary analysis: the red bars correspond to the manufacturer power curve, while the grey bars represent the experimental means of each group centered around integer values of wind speed. The error bars superimposed on each grey bar are the intervals $P_{\text {mean, }} \pm u\left(P_{\mathrm{i}}\right)$. The figure confirms the preliminary results of the other turbine under study: despite data corresponding to abnormal operation are excluded, the electrical output power remains higher than the manufacturer specifications. However, cut-in and cut-out wind speeds $(\approx 4 \mathrm{~m} / \mathrm{s}$ and $\approx 21 \mathrm{~m} / \mathrm{s}$ ) are closer to the values provided by the manufacturer.

This WT is in the area of the wind farm without a meteorological station, thus only the SM can be applied and the data after the correction are presented in Figure 13. As described in Section II, this method cannot be applied to the part of the power curve where the power is constant (nominal power); hence, wind speeds higher than rated value $(12 \mathrm{~m} / \mathrm{s})$ are excluded from the analysis. After applying the correction, the performance of the W'T (grey bars) is realistic, being lower than manufacturer curve (red bars). Two regression equations $\left(R^{2} \approx 1\right)$ are

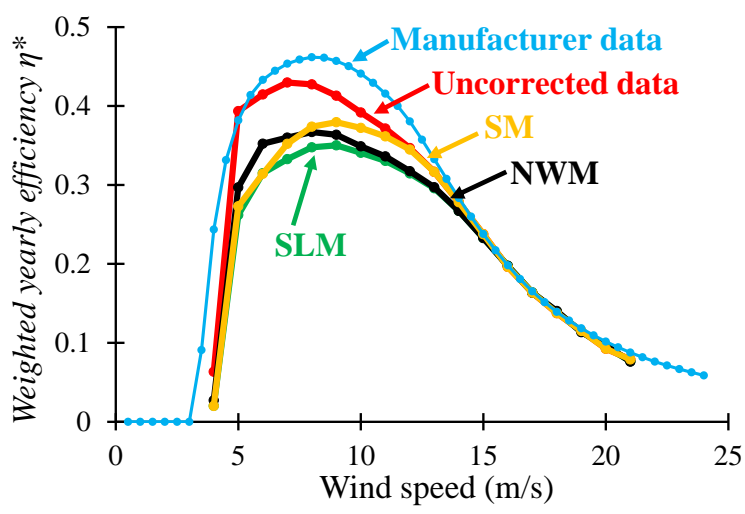

Figure 10. Turbine \#1 - Weighted yearly efficiencies for the proposed corrections.

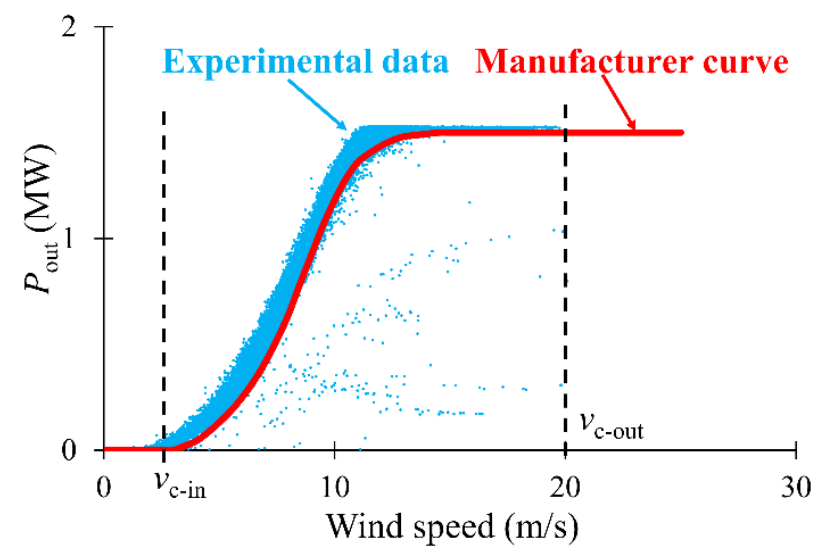

Figure 11. Turbine \#2 - Uncorrected raw experimental data (blue dots) and manufacturer power curve (red line).

determined for the wind speed intervals $<6 \mathrm{~m} / \mathrm{s}$, and between $6 \mathrm{~m} / \mathrm{s}$ and $12 \mathrm{~m} / \mathrm{s}$ :

$$
\begin{aligned}
& v_{\text {stat }}=0.946 \cdot v_{\mathrm{WT}}+1.258 ; v_{\mathrm{WT}}<6 \frac{\mathrm{m}}{\mathrm{s}} \\
& v_{\text {stat }}=0.893 \cdot v_{\mathrm{WT}}+1.923 ; 6 \frac{\mathrm{m}}{\mathrm{s}} \leq v_{\mathrm{WT}}<12 \frac{\mathrm{m}}{\mathrm{s}}
\end{aligned}
$$

The weighted yearly efficiencies for raw data are about $33.5 \%$ (wind speeds $<6 \mathrm{~m} / \mathrm{s}$ ) and $42.6 \%$ (wind speeds between $6 \mathrm{~m} / \mathrm{s}$ and $12 \mathrm{~m} / \mathrm{s}$ ). After the SM correction, the weighted efficiencies are of about $27.1 \%(<6 \mathrm{~m} / \mathrm{s})$ and $34.3 \%(6 \mathrm{~m} / \mathrm{s} \div 12 \mathrm{~m} / \mathrm{s})$, with a decrease of about $19 \%$ for both wind speed ranges.

This turbine exhibits very high energy performance in the area of the plant without the weather station. Indeed, it has the highest availability of the wind farm (99.1\%), while the average value in the second part of the plant is $97.4 \%$; moreover, its capacity factor is $27.9 \%$. This value is lower than the other WT under analysis, despite being higher than the average quantity $(20.1 \%)$ in the second area of the plant.

\section{CONCLUSIONS}

This work proposes an innovative method, named "Statistical Method" (SM), to evaluate the average efficiency of wind turbines by correcting the wind speed at the entrance of the rotor from nacelle anemometer. In the literature, other two methods (Straight Line Method, SLM, and No Wakes Method, NWM) are defined to perform this correction, taking into account technical

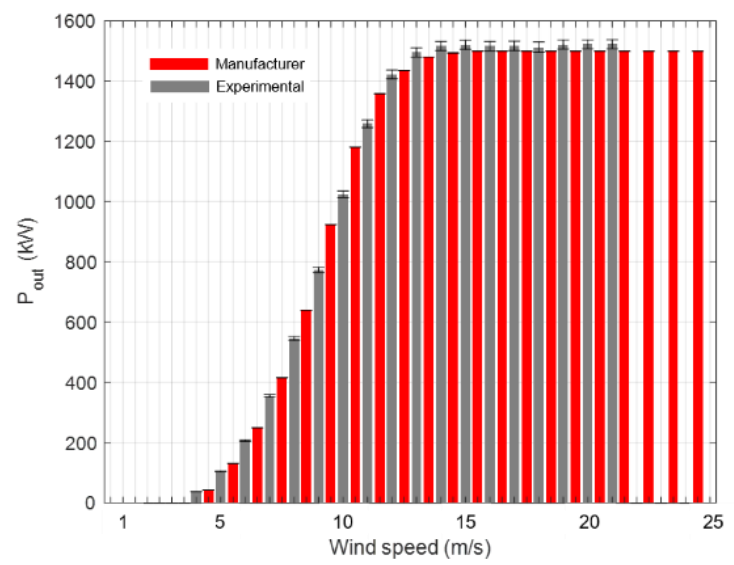

Figure 12. Turbine \#2 - Uncorrected experimental data after the preliminary data processing. 


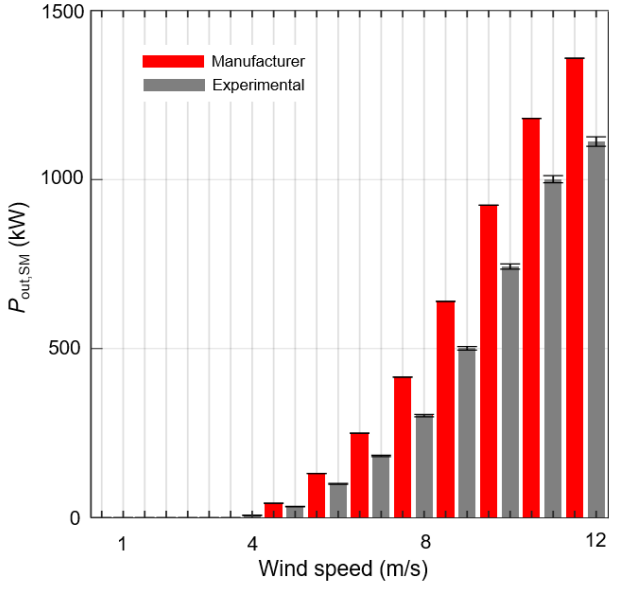

Figure 13. Turbine \#2 - SM corrected results (grey bars) and manufacturer power curve (red bars).

specifications and International Standards. These correction methods require data measured by a meteorological mast close to the turbines, but the presence of this station in wind farms is rare. Conversely, the correction proposed in this paper evaluates the wind speed entering in the WTs rotor only relying on the manufacturer power curve and the data measured by the WT anemometer. Indeed, it may be applied also in wind farms that are not equipped with a meteorological station. In the present work, these three methods were applied to a one-year experimental campaign on a wind farm in Southern Italy. In particular, two turbines located in two different areas of the same plant were analysed: only the first turbine was close to a meteorological mast. The effects of the corrections were evaluated representing the electrical output power by means of the method of bins and setting the width of the bins according to the uncertainty of the used anemometer. An uncertainty estimation was also performed for the output WT power, taking into account the power measurement uncertainty and the repeatability within each wind-speed bin. The results of the NWM were considered as a reference. Regarding the turbine in the part including the mast, the SM performed similarly to the SLM, providing comparable absolute deviations in terms of weighted efficiencies with respect to the reference. In fact, the deviations of the SM are about $\pm 7 \%$ in the total range, while the quantities corresponding to the SLM are $\pm 9 \%$ with respect to the NWM. After the SM correction, the weighted yearly efficiency decreased between about $10 \%$ and $20 \%$ with respect to raw data before correction in the usual wind speed range.

\section{REFERENCES}

[1] F. Spertino, A. Ciocia, V. Cocina, P. Di Leo, Renewable sources with storage for cost-effective solutions to supply commercial loads, Proc. of 2016 International Symposium on Power Electronics, Electrical Drives, Automation and Motion (SPEEDAM), Anacapri, Italy, 22-24 June 2016, pp. 242-247. DOI: https://doi.org/10.1109/SPEEDAM.2016.7525987

[2] A. Mahesh, K.S. Sandhu, Hybrid wind/photovoltaic energy system developments: Critical review and findings, Renewable and Sustainable Energy Reviews 52 (2015) pp. 1135-1147. DOI: https://doi.org/10.1016/i.rser.2015.08.008

[3] Z. Zhang, Y. Zhang, Q. Huang, W. Lee, Market-oriented optimal dispatching strategy for a wind farm with a multiple stage hybrid energy storage system, CSEE Journal of Power and Energy Systems 4(4) (2018) pp. 417-424.

DOI: https://doi.org/10.17775/CSEEJPES.2018.00130
[4] Wind Energy in Europe: Outlook to 2023. Online [Accessed 09 June 2021] https://windeurope.org/about-wind/reports/wind-energy-ineurope-outlook-to-2023/

[5] P. W. Carlin, A.S. Laxson, E. B. Muljadi, The History and State of the Art of Variable-Speed Wind Turbine Technology 6(2) (2003) pp. 129-159. DOI: https://doi.org/10.1002/we.77

[6] CENELEC EN 61400-12-1:2017 Power performance measurement of electricity producing wind turbines.

[7] V. Cocina, P. Di Leo, M. Pastorelli, F. Spertino, Choice of the most suitable wind turbine in the installation site: A case study, Proc. of 2015 International Conference on Renewable Energy Research and Applications (ICRERA), Palermo, Italy, 22-25 Nov. 2015, pp. 1631-1634.

DOI: https://doi.org/10.1109/ICRERA.2015.7418682

[8] A. Peña, P. E. Rethore, M. P. Van Der Lan, On the application of the Jensen wake model using a turbulence-dependent wake decay coefficient: The Sexbierum case, Wind Energy 19(4) (2016) pp. 763-776.

DOI: https://doi.org/10.1002/we.1863

[9] F. Spertino, P. Di Leo, I.S. Ilie, G. Chicco, DFIG equivalent circuit and mismatch assessment between manufacturer and experimental power-wind speed curves, Renewable Energy 48 (2012) pp. 333-343.

DOI: https://doi.org/10.1016/i.renene.2012.01.002

[10] P.J. Davis, Leonhard Euler's Integral: A historical profile of the gamma function, American Mathematical Monthly 66(10) (1959) pp. 849-869. DOI: https://doi.org/10.1080/00029890.1959.11989422

[11] K. Grogg, Harvesting the wind: The physics of wind turbines, 2005. Online [Accessed 09 June 2021] https://citeseerx.ist.psu.edu/viewdoc/download?doi=10.1.1.589. $2982 \& \mathrm{rep}=\mathrm{rep} 1 \& \mathrm{xtype}=\mathrm{pdf}$

[12] M.H. El-Ahmar, A.M. El-Sayed, A.M. Hemeida, Evaluation of factors affecting wind turbine output power, Proc. of Nineteenth International Middle East Power Systems Conference (MEPCON), Cairo, Egypt, 19-21 December 2017, pp. 1471-1476. DOI: https://doi.org/10.1109/MEPCON.2017.8301377

[13] F. Spertino, A. Ciocia, P. Di Leo, G. Iuso, G. Malgaroli, L. Roberto, Experimental testing of a horizontal-axis wind turbine to assess its performance, Proc. of $22^{\text {nd }}$ IMEKOTC4 International Symposium, Iasi, Romania, 14-15 September 2017, pp. 411-414. Online [Accessed 14 June 2021] https://www.imeko.org/publications/tc4-2017/IMEKO-TC42017-080.pdf

[14] F. Spertino, E. Chiodo, A. Ciocia, G. Malgaroli, A. Ratclif, Maintenance activity, reliability analysis and related energy losses in five operating photovoltaic plants, 2019 IEEE International Conference on Environment and Electrical Engineering and 2019 IEEE Industrial and Commercial Power Systems Europe (EEEIC / I\&CPS Europe), Genova, Italy, 11-14 June 2019, pp. 1-6. DOI: https://doi.org/10.1109/EEEIC.2019.8783240

[15] F. Spertino, E. Chiodo, A. Ciocia, G. Malgaroli, A. Ratclif, Maintenance activity, reliability, availability, and related energy losses in ten operating photovoltaic systems up to $1.8 \mathrm{MW}$, IEEE Transactions on Industry Applications 57(1) (2021) pp. 83-93. DOI: https://doi.org/10.1109/TIA.2020.3031547

[16] J. F. Manwell, J. G. Mcgowan, A. L. Rogers, Wind Energy Explained, 2010, John Wiley and Sons, Ltd, Chichester, United Kingdom, ISBN: 9780470015001.

[17] A. Carullo, A. Ciocia, P. Di Leo, F. Giordano, G. Malgaroli, L. Peraga, F. Spertino, A. Vallan, Comparison of correction methods of wind speed for performance evaluation of wind turbines, Proc. of 24th IMEKO TC4 International Symposium, 14-16 Sept. 2020, pp. 291-296. Online [Accessed 09 June 2021] https://www.imeko.org/publications/tc4-2020/IMEKO-TC42020-55.pdf 